Supporting Information

\title{
Novel Small Molecule Inhibitors of Choline Kinase Identified by Fragment-based Drug Discovery.
}

Stephan G. Zech, Anna Kohlmann, Tianjun Zhou, Feng Li, Rachel M. Squillace, Lois E. Parillon, Matthew T. Greenfield, David P. Miller, Jiwei Qi, R. Mathew Thomas, Yihan Wang, Yongjin Xu, Juan J. Miret, William C. Shakespeare, Xiaotian Zhu, and David C. Dalgarno

Table of Contents

Tables S1 - S6

Figures S1 - S6
Pages

S2 - S9

$\mathrm{S} 10-\mathrm{S} 15$ 
Table S1. Selected hits from the NMR screen, including Kd values for ChoK $\alpha$ measured by SPR (2-fold error margin), $\mathrm{IC}_{50}$ values of ChoK $\alpha$ enzyme inhibition (3-fold error margin), and binding site as determined by NMR competition experiments.

\begin{tabular}{|c|c|c|c|c|}
\hline Compound & Structure & $\mathrm{Kd}(\mu \mathrm{M})$ & $I^{\prime} C_{50}(\mu M)$ & $\begin{array}{c}\text { Binding } \\
\text { Site }\end{array}$ \\
\hline 7 & & 710 & $>2000$ & ATP \\
\hline 8 & & 194 & $>2000$ & choline \\
\hline 11 & & 132 & 87 & choline \\
\hline 12 & & 344 & 373 & choline \\
\hline 13 & & 631 & 771 & ATP \\
\hline 14 & & 1060 & $>2000$ & ATP \\
\hline 15 & & 497 & 520 & ATP \\
\hline 16 & & 479 & 348 & ATP \\
\hline 17 & & 288 & 426 & ATP \\
\hline 18 & & 468 & $>2000$ & ATP \\
\hline 19 & & 278 & $>2000$ & choline \\
\hline 20 & & 900 & 1870 & ATP \\
\hline 21 & & 1630 & $>2000$ & choline \\
\hline 22 & & 151 & $>2000$ & choline \\
\hline 23 & & 790 & 248 & choline \\
\hline 24 & & 74 & 801 & choline \\
\hline 25 & & 229 & 592 & ATP \\
\hline 26 & & 550 & $>2000$ & choline \\
\hline
\end{tabular}


Table S2. SAR by catalog. Activities of commercially available analogues of validated fragments hits selected via modeling studies (error margins: 2 to 3-fold. N.D. = not determined).

Compound
Kd $(\mu \mathrm{M})$


Table S3. Selected modifications to the quinolone ring (error margins: 2 to 3 -fold. N.D. $=$ not determined).

\begin{tabular}{|c|c|c|c|}
\hline Compound & Structure & $\mathrm{Kd}(\mu \mathrm{M})$ & IC50 $(\mu \mathrm{M})$ \\
\hline 37 & & 4.0 & 3.9 \\
\hline 38 & & 4.3 & 2.6 \\
\hline 39 & & 1.8 & 1.0 \\
\hline 40 & & 1.4 & 2.0 \\
\hline 41 & & N.D. & 15.0 \\
\hline 42 & & N.D. & 15.0 \\
\hline
\end{tabular}


Table S4. Modifications to the diazepane (error margins: 2 to 3-fold. N.D. = not determined).

\begin{tabular}{|c|c|c|c|}
\hline Compound & Structure & $\mathrm{Kd}(\mu \mathrm{M})$ & $\mathrm{IC}_{50}(\mu \mathrm{M})$ \\
\hline 50 & & N.D. & 100 \\
\hline 51 & & N.D. & $>500$ \\
\hline 52 & & N.D. & 270 \\
\hline 53 & & N.D. & $>500$ \\
\hline 54 & & N.D. & $>500$ \\
\hline 55 & & N.D. & 443 \\
\hline 56 & & N.D. & 324 \\
\hline 57 & & 8.00 & 98 \\
\hline 58 & & N.D. & $>500$ \\
\hline 59 & & N.D. & 214 \\
\hline 60 & & N.D. & $>500$ \\
\hline 61 & & N.D. & $>500$ \\
\hline 62 & & N.D. & $>500$ \\
\hline 63 & & N.D. & $>500$ \\
\hline 64 & & N.D. & $>500$ \\
\hline 38 & & 4.30 & 3 \\
\hline
\end{tabular}


Table S5. Compounds synthesized in a parallel fashion.

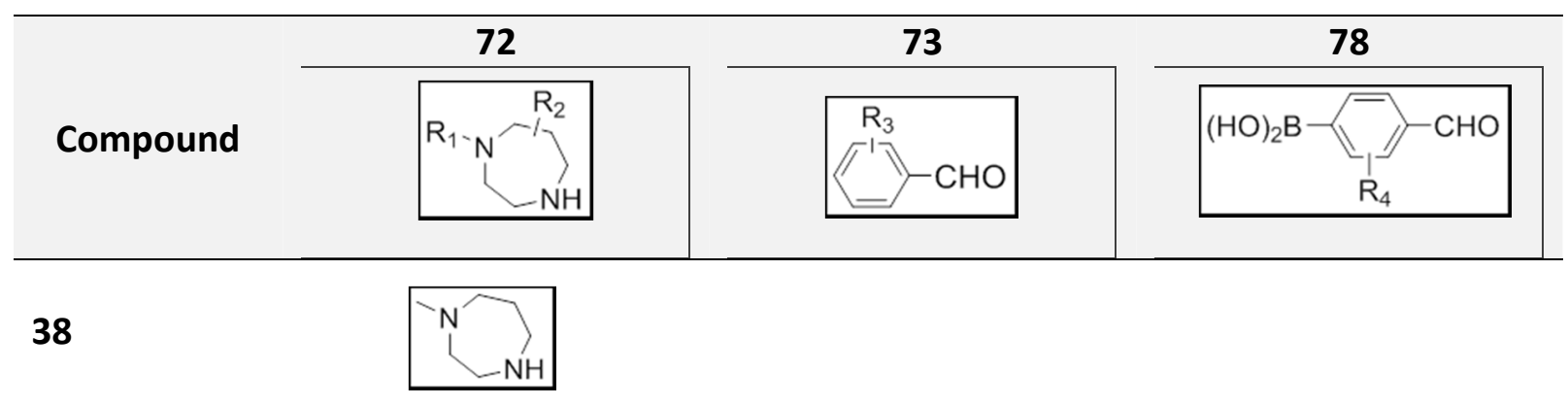

64

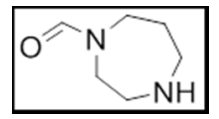

63

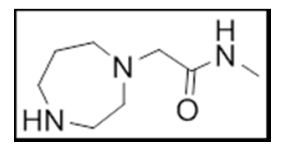

62

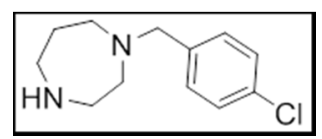

61

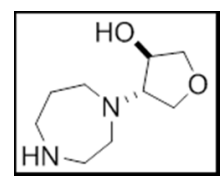

60

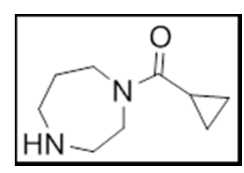

59

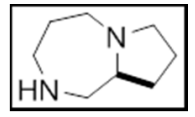

58

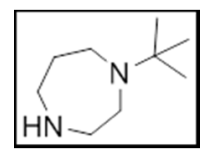

57

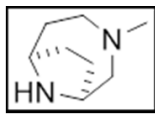


56

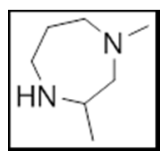

55

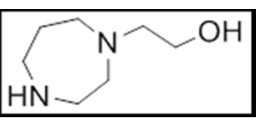

54

${ }_{\mathrm{NN}}^{\mathrm{O}}{ }^{\mathrm{O}} \mathrm{NH}_{2}$

53

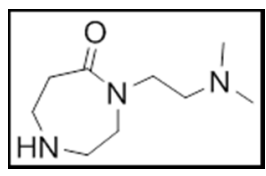

51

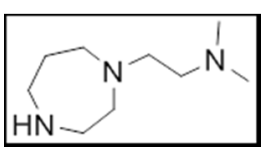

50

${ }_{\mathrm{HN}}^{\mathrm{N}}$

39

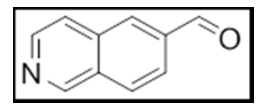

40

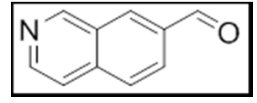

41

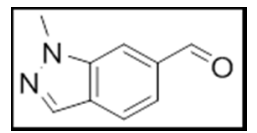

42

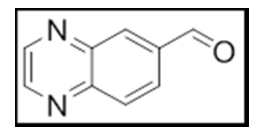

37

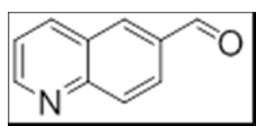




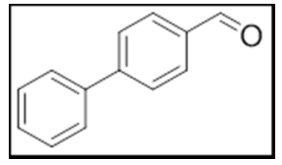

46

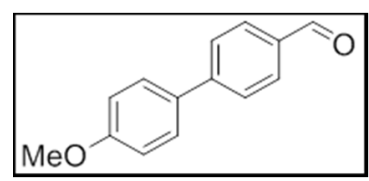

47

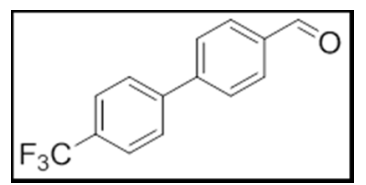

66

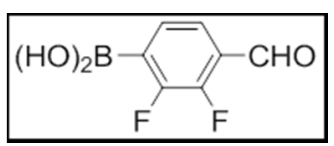

68

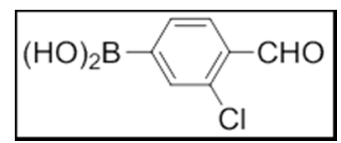

69

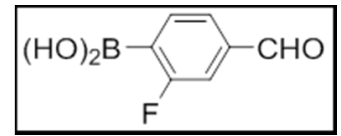

70

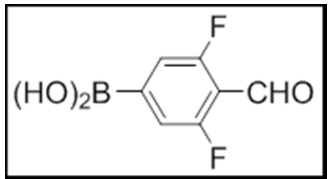


Table S6. X-ray crystal structure data collection and refinement statistics.

\begin{tabular}{|c|c|c|c|}
\hline Structure & Chok $\alpha: 11$ & Chok $\alpha: 37$ & Chok $\alpha: 65$ \\
\hline PDB entry & $5 \mathrm{EQE}$ & $5 \mathrm{EQP}$ & $5 \mathrm{EQY}$ \\
\hline \multicolumn{4}{|l|}{ Diffraction data } \\
\hline Space group & $\mathrm{P} 2{ }_{1} 2_{1} 2_{1}$ & $\mathrm{P} 2{ }_{1} 2_{1} 2_{1}$ & $\mathrm{P} 2{ }_{1} 2_{1} 2_{1}$ \\
\hline Unit cell dimensions & $\begin{array}{l}a=55.7 \AA, \\
b=120.9 \AA, \\
c=131.2 \AA\end{array}$ & $\begin{array}{l}a=55.5 \AA \\
b=120.2 \AA \\
c=130.3 \AA\end{array}$ & $\begin{array}{l}a=55.5 \AA, \\
b=121.5 \AA, \\
c=130.5 \AA\end{array}$ \\
\hline Resolution range ( $\AA$ ) (last shell) & $50-2.4(2.49-2.40)$ & $50-2.35(2.43-2.35)$ & $50-2.5(2.59-2.50)$ \\
\hline Total observation (\#) & 674,173 & $1,556,568$ & 521,721 \\
\hline Unique reflections (\#) & 35,538 & 37,205 & 31,439 \\
\hline Data completeness (\%) (last shell) & $99.3(99.8)$ & $99.7(99.5)$ & $99.5(99.9)$ \\
\hline${ }^{a} \mathrm{R}_{\text {merge }}(\%)$ (last shell) & $8.2(54.2)$ & $7.7(69.0)$ & $7.9(66.8)$ \\
\hline Intensities $I / \sigma$ (last shell) & $19.5(2.5)$ & $20.5(1.9)$ & $22.9(2.3)$ \\
\hline \multicolumn{4}{|l|}{ Refinement } \\
\hline${ }^{b} R_{\text {work }} / R_{\text {free }}(\%)$ & $22.5(26.3)$ & $22.7(26.4)$ & $22.3(27.7)$ \\
\hline No. of non-H protein atoms & 5,799 & 5,831 & 5,841 \\
\hline No. of heterogen atoms & 34 & 38 & 64 \\
\hline No. of waters & 119 & 51 & 75 \\
\hline RMS deviations in bond length $(\AA)$ & 0.007 & 0.007 & 0.007 \\
\hline RMS deviations in bond angle $\left({ }^{\circ}\right)$ & 0.96 & 1.0 & 0.97 \\
\hline Average protein B values $\left(\AA^{2}\right)$ & 35.9 & 29.1 & 31.4 \\
\hline
\end{tabular}

${ }^{\mathrm{a}} R_{\mathrm{merge}}=\sum_{\mathrm{hk}}\left[\left(\sum_{j}\left|I_{j}-<I>\right|\right) / \sum_{j}\left|I_{j}\right|\right]$.

${ }^{\mathrm{b}} R_{\text {work }}=\sum_{\mathrm{hkl}}\left|F_{o}-F_{c}\right| \sum_{\mathrm{hkl}}\left|F_{o}\right|$, where $F_{o}$ and $F_{c}$ are the observed and calculated structure factors, respectively.

${ }^{\mathrm{c}} R_{\text {free }}$ is the $\mathrm{R}$ factor calculated for a randomly selected $5 \%$ of the reflections that were omitted from the refinement. 


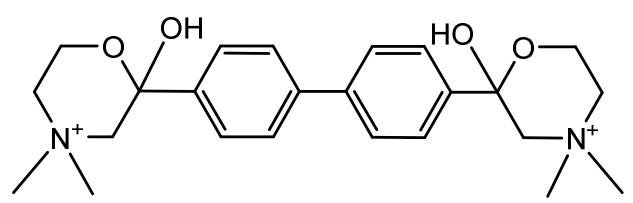

1 (HC-3)

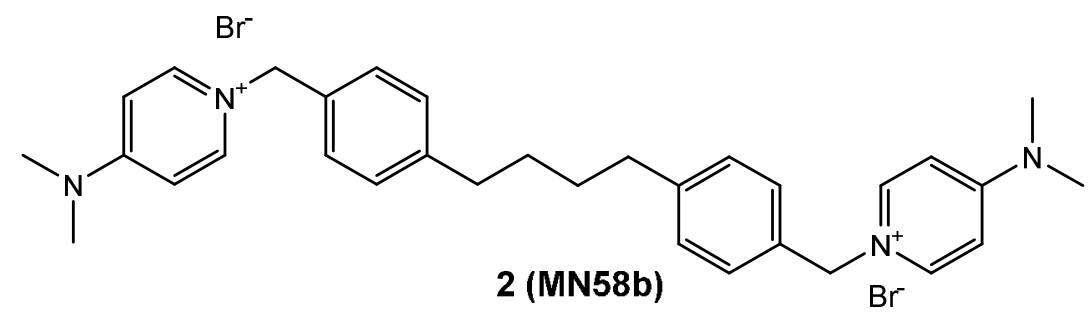<smiles>CCc1ccc(-c2nc(SCC(=O)Nc3cc(C)cc(C)c3)n[nH]2)cc1</smiles>

3 (CK37)<smiles>O[C@@](CCc1ccccc1OC1CCOCC1)(c1ccccc1)C1CN2CCC1CC2</smiles>

4 (V-11-0711)

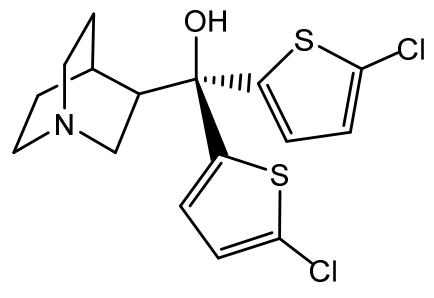

5 (V-11-023907)

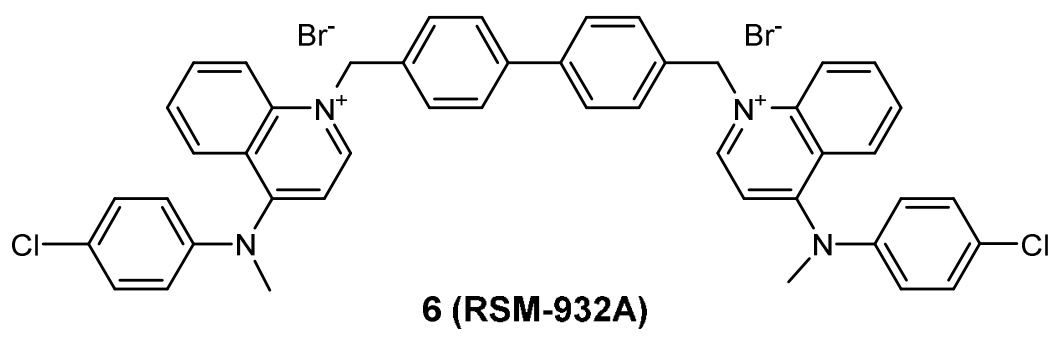

Figure S1: Structure of reference compounds discussed in this paper. 


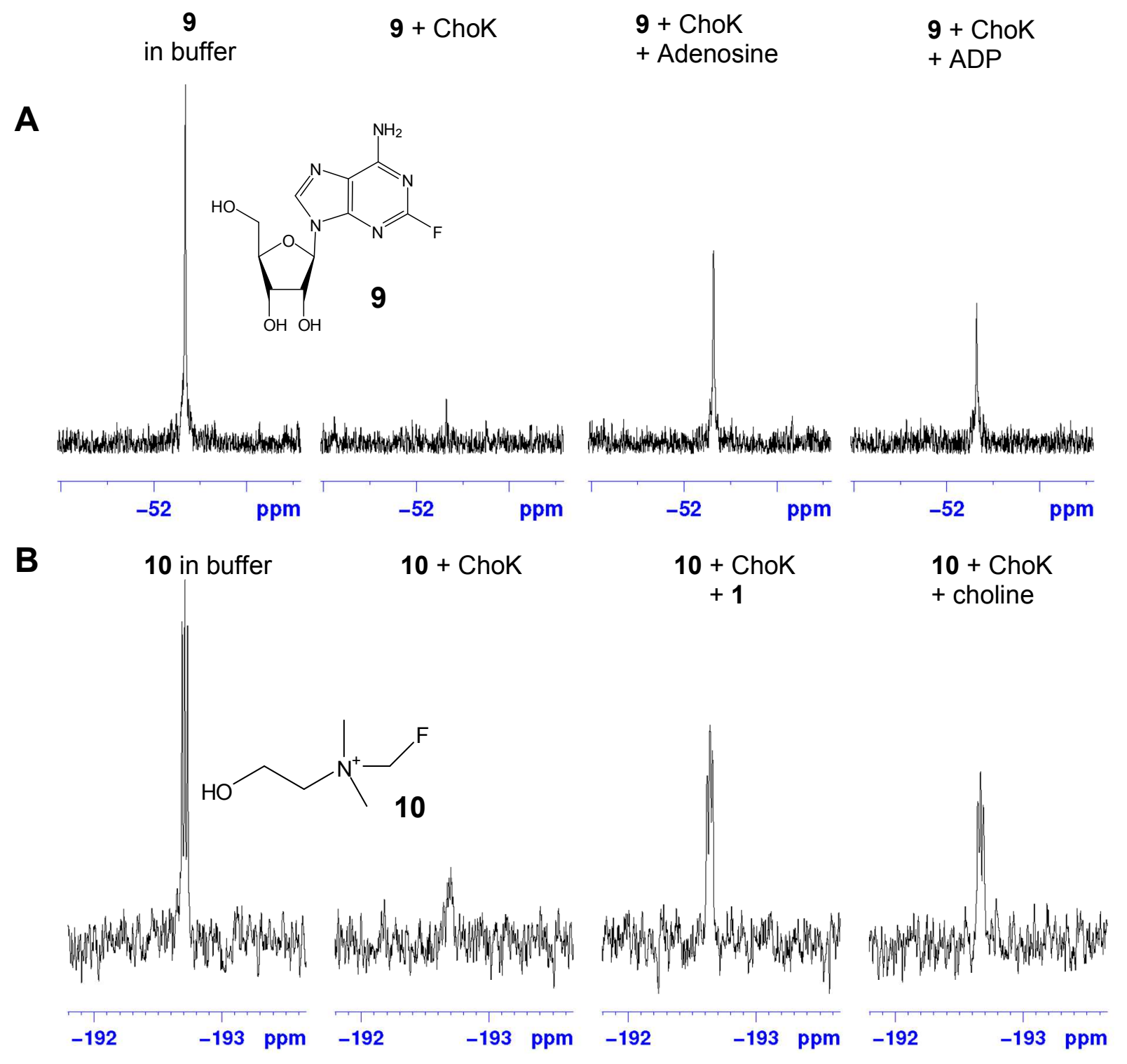

Figure S2. FAXS NMR competition assay for binding site determination. (A) ${ }^{19} \mathrm{~F}$ CPMG-NMR spectrum of $50 \mu \mathrm{M}$ of 9 in buffer. After addition of $10 \mu \mathrm{M}$ ChoKa, the signal intensity is greatly diminished due to relaxation induced by a fast exchange of 9 with the ATP site of ChoKa. Addition of ATP site competitors such as adenosine or ADP $(2 \mathrm{mM})$ partially recovered the NMR signal due to displacement of $\mathbf{9}$ from the ATP site. (B) Similar competition experiments were performed with compound 10. The ${ }^{19} \mathrm{~F}$ NMR spectrum observed for $50 \mu \mathrm{M}$ of $\mathbf{1 0}$ in buffer is attenuated in the presence of $10 \mu \mathrm{M} \mathrm{ChoK \alpha}$, and partially recovered by $2 \mathrm{mM}$ addition of competitive binders to the substrate site, such as $\mathbf{1}$ or choline. 


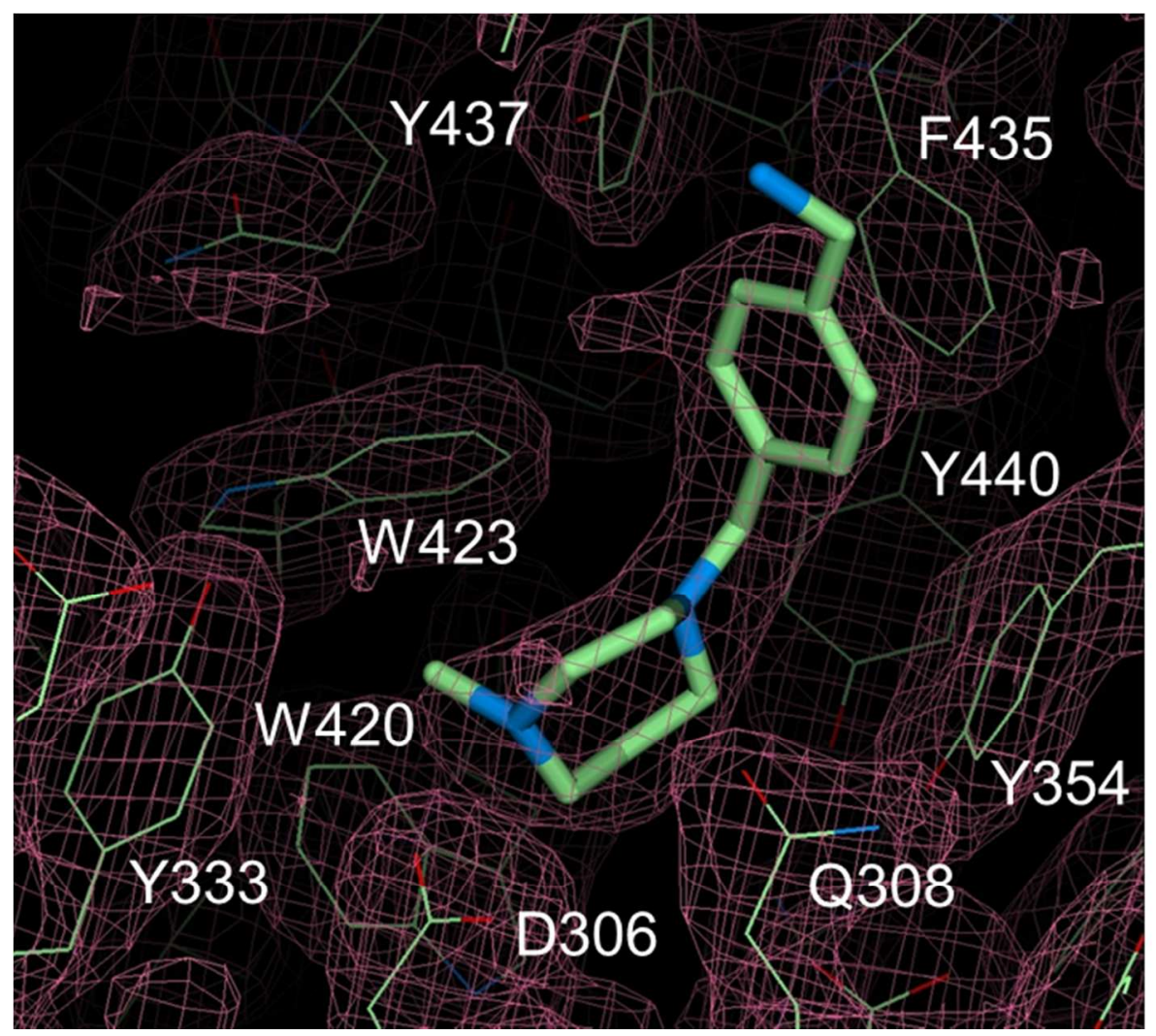

Figure S3. Electron density map (2fo-fc) contoured at $1.0 \sigma$ showing the well bound compound 11 in the choline site. Prepared with Quanta (Accelrys). 


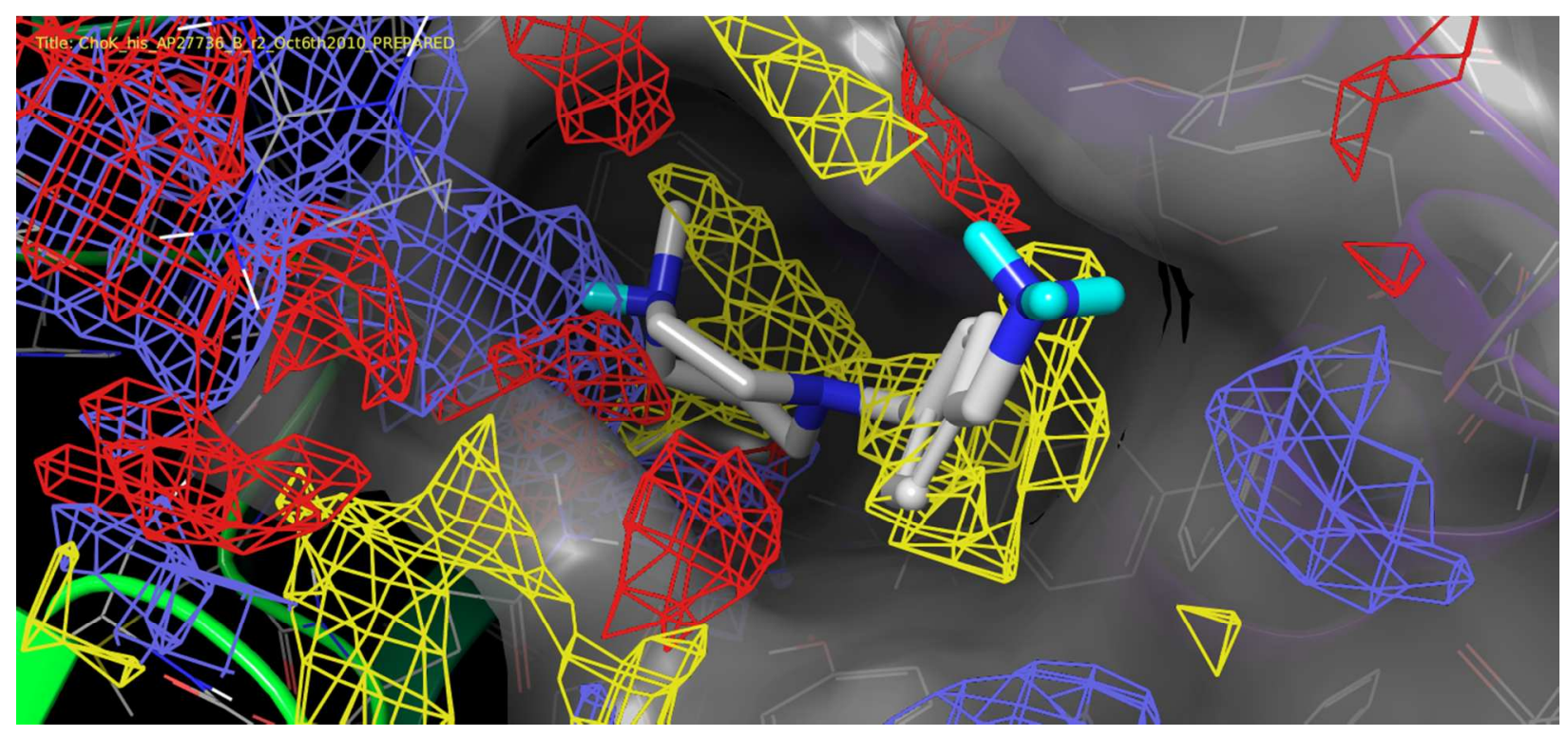

Figure S4. SiteMap rendering of the binding site based on the X-ray crystal structure of ChoK $\alpha$ with compound 11. The mesh maps indicate areas of the binding site that can accommodate a hydrogen bond acceptor (red), hydrogen bond donor (blue), or a hydrophobic group of a ligand (yellow). 


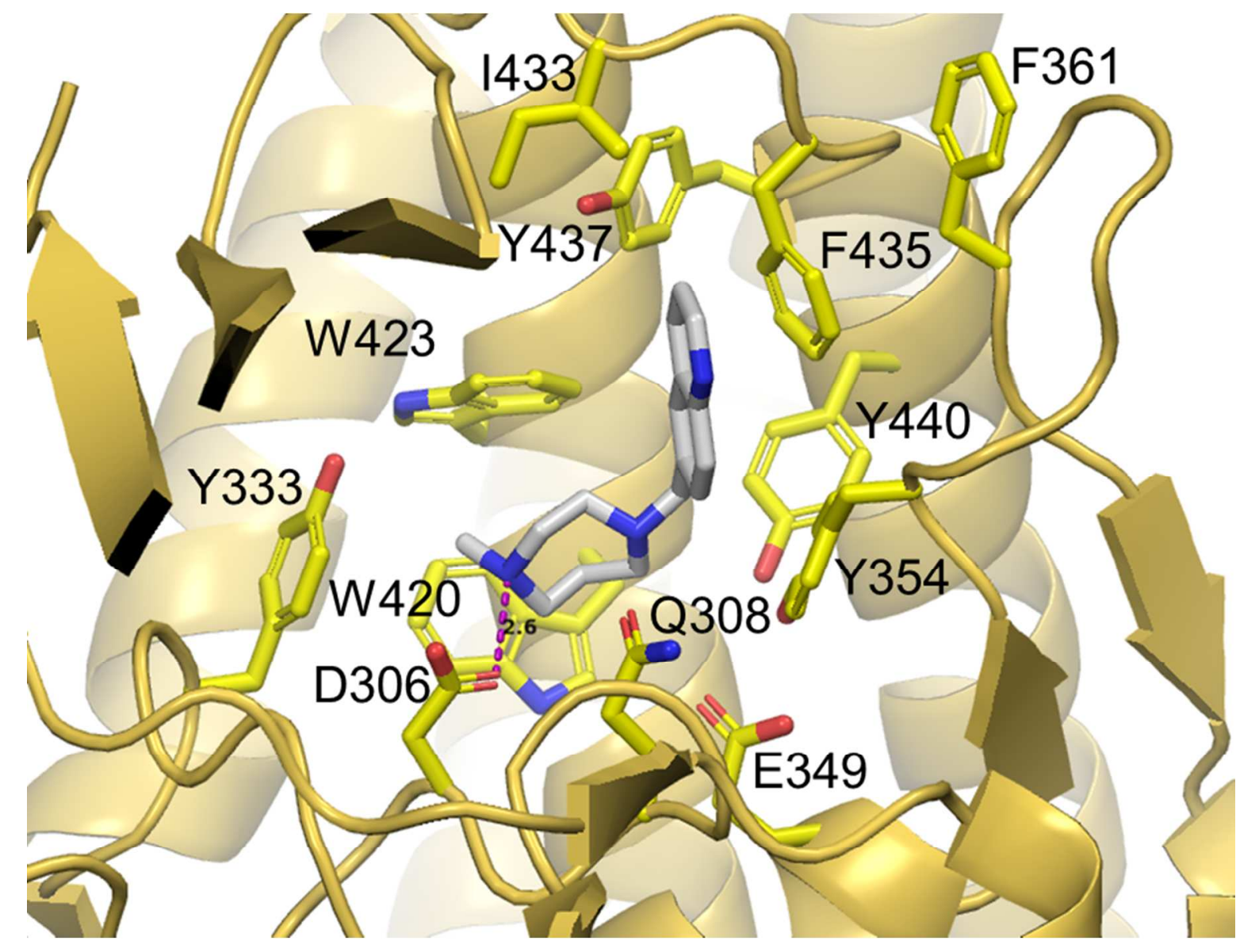

Figure S5. Binding mode of $\mathbf{3 7}$ in the substrate site of ChoK $\alpha$ (PDB entry 5EQP). ChoK $\alpha$ is shown in yellow and compound $\mathbf{3 7}$ in light gray. 


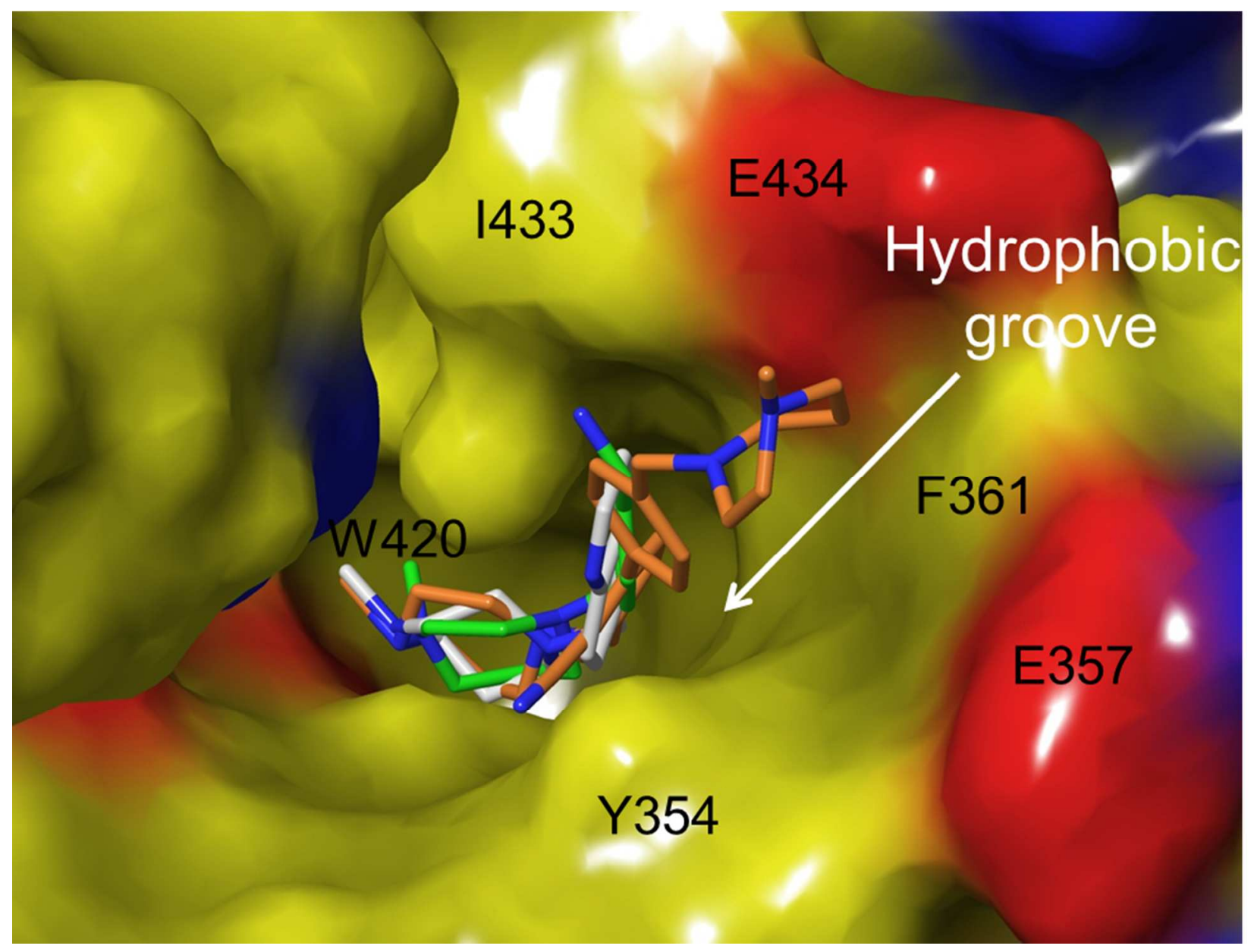

Figure S6. Comparison of binding mode of ChoK $\alpha$ inhibitors: 11 (green), 37 (gray) and 65 (orange). Surface representation of $\mathrm{ChoK} \alpha$ colored on the basis of residue charge around the choline binding site, prepared in maestro (Schrodinger). Red color indicates negative charge and blue positive. The $2^{\text {nd }}$ diazepane moiety binds close to the solvent front and is surrounded by negatively charged residues (E434 and E357). 